\title{
A comparison between different selection indices for some productive traits on Egyptian buffaloes
}

\author{
KAWTHER ABEL MONIEM MOURAD ${ }^{1}$ and ADEL SALAH KHATTAB ${ }^{2}$ \\ 'Animal production Research Institute, Ministry of Agriculture, Dokki, Cairo, Egypt, ${ }^{2}$ Animal Production Department, \\ Faculty of Agriculture, University of Tanta, Tanta, Egypt
}

\section{Abstract}

A total of 2262 normal lactation records of Egyptian buffaloes kept at Mehallet Mousa Farm belonging to Animal Production Research Institute, Ministry of Agriculture during the period from 1985 to 2003 were used to estimate phenotypic and genetic parameters for total milk yield (TMY, kg), lactation period (LP, day), birth weight (BW, kg) and weaning weight (WW, kg). In addition, eleven selection indices were constructed. Data were analyzed using multi trait animal model (MTAM). The model included individuals, permanent environmental and errors as random effects, month and year of calving and parity as fixed effects.

Heritability estimates were $0.172,0.134,0.046$ and 0.257 for TMY, LP, BW and WW, respectively. Genetic correlations among all traits studied are positive highly significant and ranged from 0.50 to 0.99 . Permanent and temporary environmental correlations among all traits studied are similar to genetic correlations, while the correlations between WW and all traits studied are negative. Eleven selection indices were constructed, index $\mathrm{I}_{1}$ which incorporating TMY, LP, BW and WW or index $\mathrm{I}_{2}$ which incorporating TMY, LP and WW are the best $\left(R_{H H}=0.86\right)$, both indices are recommended to improve productive traits in Egyptian buffaloes.

Keywords: buffalo, milk yield, lactation period, birth weight, weaning weight, selection indices, Egypt

\section{Zusammenfassung}

\section{Vergleich von Selektionsindizes mit ausgewählten Leistungsmerkmalen bei Ägyptischen Büffelkühen}

Genutzt wurden 2262 Laktationsabschlüsse Ägyptischer Büffelkühe aus den Jahren 1985 bis 2003, die in der Mahallet Mousa Farm des Forschungsinstitutes für Tierproduktion gehalten wurden. Die Schätzung phänotypischer und genetischer Parameter erfolgte bei den Merkmalen Gesamtmilchertrag (TMY, kg), Laktationsperiode (LP, Tag), Geburts- (BW, $\mathrm{kg}$ ) und Absatzgewicht (WW, kg). Es wurden 11 Selektionsindizes konstruiert und verglichen. Für die Datenanalyse wurde das Mehrmerkmalstiermodell genutzt. Die Schätzwerte für die Heritabilität lagen in der Reihenfolge TMY, LP, BW und WW bei 0,172, $0,134,0,046$ und 0,257 . Die genetischen Korrelationen zwischen allen einbezogenen Merkmalen waren signifikant positiv und lagen bei 0,50 bis 0,99. Die Umweltkorrelationen waren ähnlich den genetischen. Die Beziehungen zwischen WW zu allen 
anderen Merkmalen lagen im negativen Bereich. Von den 11 Selektionsindizes erwiesen sich der Index $I_{1}$, mit den Merkmalen TMY, LP, BW und WW sowie der Index $I_{3}$ mit den Merkmalen TMY, LP und WW als die besten $\left(\mathrm{R}_{\mathbb{H}}=0,86\right)$ und sind zur Verbesserung bei den hier ausgewählten Produktionsmerkmalen zu empfehlen.

Schlüsselwörter: Büffelkuh, Milchertrag, Laktationsperiode, Geburtsgewicht, Absatzgewicht, Selektionsindex, Ägypten

\section{Introduction}

The total population of river buffaloes in Egypt is 3.8 million head according to MALR (2006) and represented to $46.81 \%$ of the total population of dairy animals. Buffaloes produce $56 \%$ of the total milk production. Buffalo milk is characterized by high fat percent $(7 \%)$ and solids not fat $(16 \%)$ contents, white colour, good flavour compared with cattle. Therefore buffalo is considered the main dairy animals in Egypt.

The selection index is a method for estimating the breeding value of an animal combining all information available on the animal and its relatives (MORDE 1996). On other words, HAZEL and LUSH (1942) showed that the selection index was the most efficient method for selection in farm animals for several traits. In addition, selection based on a multi trait animal model is considered as the best way to select cows for economically important traits (ALBUQUERQUE et al. 1995). In Egypt few studies have been carries out to construct selection indices for economic traits on Egyptian buffaloes (i.e. EL-ARIAN et al. 2001).

The traits to be considered in selection may not be equally important and this requires some kinds of weightings. The amount of weight given to each trait depends up on its relative economic value, genetic, phenotypic variances and co variances with other traits. Several workers constructed selection indices in water buffalo based upon cost of milk production or selling price of milk rather than net profit from milk and as a result the estimates were unrealistic (EL-ARIAN et al. 2001).

EL-ARIAN (2005) constructed 26 selection indices for milk traits of Friesian cattle in Egypt, using two methods for estimating relative economic values:

(1) actual relative economic values which was based on the net profit from one unit of each trait, according to estimates of animal husbandry section, Sakha station and the prices of some commercial farms in Northern Delta in Egypt and

(2) relative weight which calculated as $1 / \sigma p$, where op is phenotypic standard deviation of each trait according to FALCONER and MACKAY (1996).

He found that rank correlation coefficient between the ranking 598 Friesian cows by the both methods of relative economic values was 0.95 . Thus the second method of relative economic values was recommended for ease of calculation.

The main objectives of this study were:

(1) estimate phenotypic and genetic parameters for total milk yield (TMY), lactation period (LP), birth weight (BW) and weaning weight (WW) and

(2) construct a set of selection indices by using relative weight to be used for the improvement of productive traits in Egyptian buffaloes under local conditions. 


\section{Material and methods}

\section{Description of data}

Data used in the present investigation comprised 2262 normal lactation records of Egyptian buffaloes kept at Mehallet Mousa farm, belonging to Animal Production Research Institute, Ministry of Agriculture, Dokki, Cairo, Egypt, during the period from 1985 to 2003. Cows were mated naturally. Artificial insemination was only practiced when there was a probably of genital disease infection. Heifers were served for the first time when they reached 24 months or $350 \mathrm{~kg}$. Pregnancy was detected by rectal palpation 60 days after the last service. Abnormal records affected by disease or by abortion were excluded. Editing consisted of accepting only lactations having more than 150 and less than 400 days of lactation and from cows having a known registered sire and dam with a total of more than five paternal half-sisters. Traits studied are TMY, LP, BW and WW. Calves were allowed to suckle their dam's colostrums for the first three days after birth. Therefore they were artificially reared on natural milk twice daily on the age basis till weaning at the age of 15 weeks. Animals were grazed on Egyptian clover berseem (Trifolium alexandrinum) during December to May. During the rest of the year the animals were fed on concentrate mixture with Rice Straw. Cows producing more than $10 \mathrm{~kg}$ a day and those that are pregnant in the last two months of pregnancy were supplemented with extra concentrate ration. Buffaloes were hand milked twice a day. Table 1 show the data structure considered in the analysis, means, standard deviations and coefficients of variability of traits studied.

Table 1

Structure of data used in analysis

Datenstruktur

\begin{tabular}{lccrr}
\hline & Number & Mean & SD & CV \\
\hline Traits & & & & \\
Total milk yield, kg & 2262 & 1427 & 742 & 52 \\
Lactation period, d & 2262 & 184 & 80.30 & 44 \\
Birth weight, kg & 2262 & 34.17 & 6.71 & 20 \\
Weaning weight, kg & 1149 & 91.15 & 7.75 & 9 \\
Observations & & & & \\
$\quad$ Cows & 849 & & & \\
Sires & 351 & & & \\
Dams & 696 & & & \\
Iterations & 172 & & & \\
Mixed Model Equations (MME) & 10516 & & & \\
Animal in relationship matrix (A $\left.{ }^{-1}\right)$ & 1896 & & & \\
\hline
\end{tabular}

Mean unadjusted mean, SD standard deviation, CV\% coefficient of variability

\section{Analysis}

Preliminarily analysis by using Statistical Analysis System (SAS) version 8.2 for Windows were used to study the fixed effects of month and year of calving and parity, all effects are significant effect $(P<0.01)$ on all traits studied (i.e. TMY, LP, BW and WW). Estimation of variance components and genetic parameters were estimating by using multi trait animal model, by using the program of VCE 4 (version 4.2.5) and PEST program (PEST) 
(GROENEVELD et al. 1998). Model in the analysis included, individual, permanent environmental and errors as random effects, month of calving, year of calving and parity as fixed effects.

\section{Constructed selection indexes}

The estimates of phenotypic and genetic variances and covariances for TMY, LP, BW and WW were used for the construction of several selection indices.

Relative economic weight (REV) was calculated as 1/op, where op is phenotypic standard deviation of each trait (FALCONER and MACKAY 1996). Setting the economic value of TMY as unity the REV of LP, BW and WW are 9.24, 110.58 and 95.74, respectively.

The principle of selection by means of an index developed by HAZEL (1943) was followed in deriving the different indices used in this study. Some modifications of this method were suggested by HENDERSON (1963). The basic index including the four traits was calculated using the matrix technique as described by CUNNINGHAM (1972). In addition, to the complete index, then reduced indices were computed using all combinations of traits. These indices were compared via the correlation with the aggregate genotype $\left(R_{H H}\right)$. The partial regression coefficients (b's) were computed as $b=P^{-1} G a$, where $P^{-1}$ is the inverse of $P$ (in matrix notation). The correlation between the calculated index with total aggregate genotype $\left(R_{H H}\right)$ was estimated as $R_{H H}=\sigma l / \sigma H$. Expected genetic change in any one of the traits included in the aggregate genotype was calculated according to KHATTAB and SULTAN (1991). The intensity of selection for a trait was set to be 1.00 for the purpose of comparison only.

\section{Results and discussion}

\section{Means}

Means, standard deviation (SD) and coefficient of variation (CV\%) for TMY, LP, BW and WW are presented in Table 1. The present mean of TMY was $1427 \mathrm{~kg}$ produced in an average lactation period of 184 days. The present mean of TMY is higher than that of MOSTAGEER et al. (1981) $1160 \mathrm{~kg}$ in 199 days in Egyptian buffaloes, while the present means of TMY and LP are lower than those estimates reported by TONHATI et al. (2000) and GHAFFAR et al. (2007) working on Murrah buffaloes in Brazil, and Kundhi buffaloes in Pakistan, being $1497 \mathrm{~kg}$ and $1356 \mathrm{~kg}$ for milk yield and 271 days, and 219 days for lactation length, respectively. Also, ROSATI and VAN VLECK (2002) with Italian river buffaloes found that average total milk yield was $2287 \mathrm{~kg}$. Means of BW and WW are similar to the estimate of $33 \mathrm{~kg}$ and $87 \mathrm{~kg}$ reported by EL-AWADY et al. (2005) using another set of Egyptian buffaloes. The large CV\% value for TMY and LP (52 and 44\%, respectively, Table 1) reflect a great variation between individuals in important productive traits.

\section{Genetic parameters}

Estimates of variance components and genetic parameters for TMY, LP, BW and WW are shown in Tables 2 and 3. Heritability $\left(\mathrm{h}^{2}\right)$ estimates for TMY and LP seem to be low $(0.172$ and 0.134 , respectively), especially if compared to estimates from similar analysis for dairy cattle. Egyptian buffaloes have not been intensively selected in the past, so greater 
genetic variability among animals would be expected. The variation in production can be assigned mainly to environmental effects causing low heritability estimates. The temporary environmental effects on TMY, LP and BW were higher $(0.67,0.71$ and 0.89 , respectively, Table 3). Similar results are obtained by ROSATI and VAN VLECK (2002) working on Italian river buffaloes found that $h^{2}$ estimates for milk yield was 0.14 and they concluded that progress due to selection might be slow if traditional selection schemes are used to improve quantity and quality of milk to produce mozzarella cheese. Better identification will improve the genetic trend of the population. Alternative selection schemes that make use of techniques to overcome the problem of misleading genealogies may need to be further developed.

Table 2

Estimates of heritability (on diagonal), genetic correlations (below diagonal), permanent correlations (above diagonal) and environmental correlations (between parenthesis) between traits studied Heritabilitätsschätzwerte (diagonal) genetische Korrelation (unterhalb der Diagonale) phänotypische Korrelation (oberhalb der Diagonale), Umweltkorrelation in Klammern

\begin{tabular}{lllll}
\hline Traits & TMY & \multicolumn{1}{c}{ LP } & BW & WW \\
\hline TMY & 0.172 & $0.97(0.85)$ & $0.23(0.19)$ & $-0.47(-0.50)$ \\
LP & 0.94 & 0.134 & $0.05(0.07)$ & $-0.45(-0.88)$ \\
BW & 0.50 & 0.76 & 0.046 & $-0.73(0.120)$ \\
WW & 0.99 & 0.98 & 0.62 & 0.257 \\
\hline
\end{tabular}

In addition, KHATTAB and MOURAD (1992) using another set of Egyptian buffaloes, found that $\mathrm{h}^{2}$ estimates for TMY and LP were 0.17 and 0.13 , respectively. They concluded that selection based on the phenotypic merit of the animal would not be effective. Information on the pedigree combined with the phenotypic of the individual may be used for selection of females in the initial stages, while progeny testing will be the right procedure for the selection of bulls. Also, GANDHI (2002) with 316 first lactation records of Murrah buffaloes found that $\mathrm{h}^{2}$ estimates for first lactation milk yield and first lactation length were 0.1408 and 0.1479 , respectively. In addition, low estimates of $h^{2}$ for milk yield and lactation period were reported by THEVAMANOHARANA (2002) working on 3195 lactation records of 1183 Nili-Ravi buffaloes. The authors suggested that most of the observed variation in milk trait collateral relatives and progeny test should be used in selection programs. The improvement of these traits may be achieved by better environmental conditions, i.e. better feeding, better management, reduction of heat stress, better control of diseases including vaccination programs and wide spread, milk recording and testing systems.

On the other hand, TONHATI et al. (2000) on Murrah buffaloes in Brazil found that $\mathrm{h}^{2}$ estimate for TMY was 0.38 . The authors concluded that the genetic change for milk yield is possible by selecting the most productive animals. The same authors also found that $\mathrm{h}^{2}$ estimate for LP was 0.01, which indicated that the genetic variation among individuals is practically nil. Individual differences with respect to this could be reduced by management and breeding practices.

Heritability estimates for BW and WW are 0.046 and 0.257 , respectively (Table 2). The moderate $h^{2}$ estimate for WW suggested that efforts could be made to bring about improvement weaning weight through individual selection as well as better managerial 
practices. MAHDY et al. (1999) using another set of Egyptian buffaloes, found that $\mathrm{h}^{2}$ for BW was 0.10. EL-AWADY et al. (2005) with 5404 Egyptian buffalo calves, using multi trait animal model, found that $h^{2}$ estimates for WW was 0.36 .

While higher estimate of $h^{2}$ for BW were reported by EL-AWADY et al. (2005) (0.35) using another data from three farms of Egyptian buffaloes, while this study had data from one farm only, which might explain the difference in heritability. In addition, CASSIANO et al. (2004) working on buffaloes in Brazilian Amazon, reported that the Murrah breed showed the highest $\mathrm{h}^{2}$ for BW (0.62) compared with 0.38 in Jafarabadi breed. They concluded permanent environmental effects on the BW were low (0.00 to 0.16) in all breeds studied. In addition, GROEN and VOS (1995) with 631 Dutch Black and White growing dairy heifers, found that $h^{2}$ for BW was 0.46 .

\section{Correlations}

Estimates of genetic, permanent environmental and temporary environmental correlations among all traits studied are presented in Table 2. All genetic correlations between traits are positive, highly significant and being $0.94,0.50$ and 0.99 between TMY and each of $L P$, BW and WW and being 0.76 and 0.98 between LP and each of BW and WW, and the genetic correlation between BW and WW was 0.62 (Table 2). The present estimates are similar to those that found in the literature for dairy cattle. In this respect, KHATTAB and MOURAD (1992) and ATIL et al. (2005b) found that the genetic correlation between TMY and LP were 0.62 and 0.90, respectively. MAHDY et al. (1999) with Egyptian buffaloes, found that the genetic correlation between TMY and each of BW and WW were 0.59 and 0.27 , respectively and between LP and each of BW and WW were 0.68 and 0.39 , respectively. EL-AWADY et al. (2005) found that the genetic correlation between BW and WW was 0.41. ATIL et al. (2005a) with Friesian found that the genetic correlation between BW and WW 0.80 . The present results indicated that higher productive cows were lactating for longer period and selection for high milk yield brings correlated response for lactation period and heavier weight at birth and weaning. On other words, the present results showed that improvement of milk production and weaning weight through selection is possible. Genetic progress can be achieved if the farms adopt tests for the genetic evaluation of sires.

Estimates of permanent and temporary environmental correlations between TMY and each of LP and BW are nearly similar to genetic correlation as shown in Table 2. Similar results were reported by MAHDY et al. (1999) on Egyptian buffaloes. The present results lead to state that an improvement in environment (i.e. management, feeding, housing, ..., etc) will increase milk yield, lactation period and birth weight of calves. Estimates of permanent and temporary environmental correlations between WW and each of TMY, LP and BW were negative and unexpected. Lower or higher correlations estimates stated the small or large environmental effects on concerned traits.

\section{Selection indices}

Estimates of genetic and phenotypic variances and covariances for TMY, LP, BW and WW were used for the construction of several selection indices (Table 3). Eleven selection indices were constructed (Table 4). The original index $\left(l_{1}\right)$ included all the four variables 


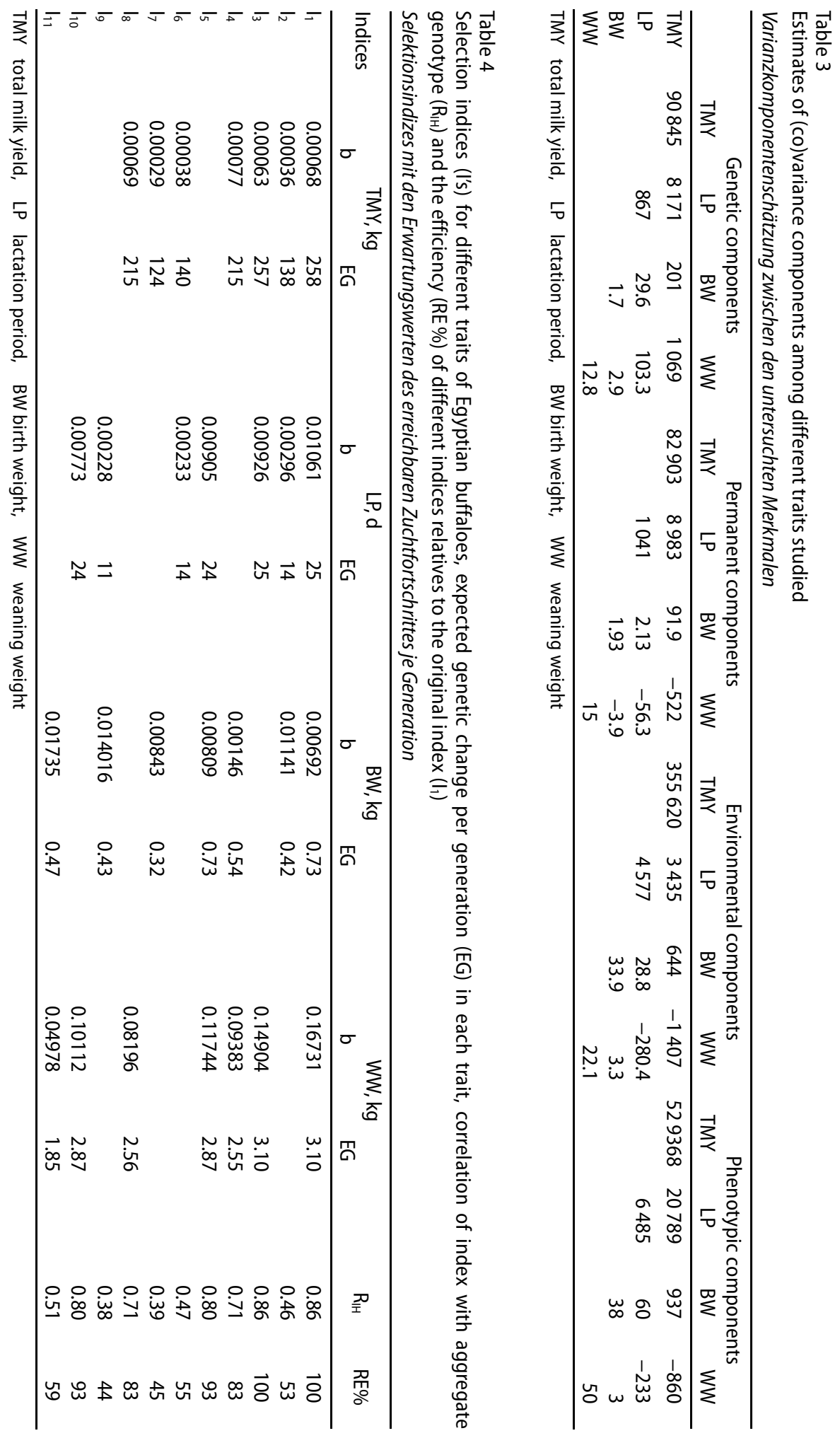


(i.e. TMY, LP, BW and WW) to be used for improving the aggregate genotype of the four traits, while, the reduced indices $\left(I_{2}, l_{3}, \ldots, I_{11}\right)$ included only three or two variables to select aggregate genotype.

The expected genetic gain per generation in each variate (TMY, LP, BW and WW) assuming a selection intensity 1 given in Table 4 . The expected genetic change per generation (EG) ranged from 124 to $258 \mathrm{~kg}$ for TMY, from 11 to 25 days for LP, from 0.32 to $0.73 \mathrm{~kg}$ for BW and from 1.85 to $3.10 \mathrm{~kg}$ for WW. The present estimates for TMY and LP are higher than those reported by EL-ARIAN et al. (2001) working on 1247 normal first lactation of Egyptian buffaloes, constructed four selection indices involving all combinations of two or three traits (TMY, LP and age at first calving), reported that the expected genetic gain per generation for TMY ranged from 56.54 to $68.66 \mathrm{~kg}$ and for LP ranged from 1.78 to 11.20 days.

The maximum genetic improvement in TMY, LP, BW and WW was achieved by the original index $\left(\mathrm{I}_{1}\right)$. The expected genetic gain in TMY increased by $258 \mathrm{~kg} /$ generation, LP increased by 25 days, BW increased by $0.73 \mathrm{~kg}$ and WW increased by 3.10 . Also, the third index $\left(I_{3}\right)$, which included TMY, LP and WW was similar to the original index $\left(I_{1}\right)$ in expected genetic gain and equal for $R_{\mathbb{H}}$ ( 0.86 , Table 4$)$.

Indices not including WW $\left(I_{2}, I_{6}, I_{7}\right.$ and $\left.I_{9}\right)$ showed reduced of accuracy $0.46,0.47,0.39$ and 0.38 , respectively (Table 4). Including WW with TMY and or LP $\left(I_{2}, I_{10}\right)$ closed in accuracy to $I_{1}$. Hence, it would be desirable to include WW in an index incorporating TMT and LP.

Compare of selection indices indicates that index $I_{1}$, which incorporated TMY, LP, BW and WW and the third index $I_{3}$, which incorporated TMY, LP and WW are the best $\left(R_{\mathbb{H}} 0.86\right.$, Table 4). These indices are recommended for Egyptian buffaloes and both indices are very simple and easy to construct.

In conclusion low heritability estimates for milk yield, lactation period and birth weight may be due to little direct genetic selection has been effected. Utilization of artificial insemination needs to be increased in order to increase genetic exchange among herds and to increase rate of genetic improvement. Improvement in identification of parents might be a cost effective way to increase heritability and to increase the rate of genetic improvement High genetic improvement for milk yield, lactation period, birth weight and weaning weight was achieved by indexes $I_{1}$ and $l_{3}$.

\section{References}

Albuquerque LG, Dimov G, Keown GF, Van Vleck LD (1995) Estimates using an animal model (co)variances for yields of milk fat and protein for the lactation of Holstein cows in California and New York. J Dairy Sci 78, 1591-6

Atil H, Khattab AS, Badawy L (2005a) Genetic parameter of birth and weaning weights for Friesian calves by using an Animal model. Arch Tierz 48, 209-18

Atil H, Khattab AS, Gerekei G (2005b) A Comparison of different selection indices for genetic improvement of some dairy milk traits in Holstein Friesian cows in Turkey. J Appl Anim Res 27, 117-20

Cassiano LA, Mariante AS, McManusc, Marques JRF, Costa NA (2004) Genetic parameters of production and reproduction traits of buffaloes in the Brazilian Amazon. Pesquisa Agropecuria Brazileria. Empresa Brasileria de Pesquisa Agropecuaria, Brasileria Brazil 39, 451

Cunningham EP (1970) Theory and application of statistical selection methods. XIV. British poultry breeders round table. Birmingham, 14-6 
El-Arian MN (2005) Selection indices for Friesian cows using two methods of calculating relative economic values for some important productive and reproductive traits. J Agric Sci, Mansoura Univ Egypt 30, 7285-96

El-Arian MN, Mourad KA, Khattab AS (2001) A comparison of different selection indices for genetic improvement of some milk traits in a herd of Egyptian buffaloes. J Agric Sci, Mansoura Univ Egypt 26, 2687-95

El-Awady HG, Shalaby NM, Mourad KA (2005) Variance components due to direct and maternal effects and estimation of breeding values for some growth of Egyptian buffaloes. J Agric Sci, Mansoura Univ Egypt 30, 7425-36

Falconer DS, Mackay TFC (1996) Introduction to quantitative genetic. 4th ed, Longman Group UK Harlow

Gandhi RS (2002) Evolving Multi - trait selection criteria in Murrah buffaloes. Buffalo J 2, 182-92

Ghaffer A, Ansari MH, Jokhio MH, Bhutto NM (2007) Genetic analysis of a purebred herd of Kundhi buffaloes in Pakistan. Italian J Anim Sci 6, 271-4

Groen AF, VOS H (1995) Genetic parameters for body weight and growth in Dutch Black and White replacement stock. Livest Prod Sci 41, 201-6

Groeneveld E, Kovac M, Wang T (1998) PEST User Manual A software package for multivariate and estimation, University of Illinois, Urbana, IL, USA

Hazel LN (1943) The genetic basis constructing selection indices. Genetics 28, 476

Hazel LN, Lush JL (1942) The efficiency of three methods of selection. J Heredity 33, 393

Henderson CR (1963) Selection index and expected genetic advance. Statistical Genetics and plant breeding. NAS NRC, 982

Khattab AS, Mourad KA (1992) Estimation of genetic parameters and genetic trends for some milk traits in a herd of Egyptian buffaloes. Egypt J Anim Prod 29, 33-44

Khattab AS, Sultan ZA ( 1991) A comparison of different selection indices for genetic improvement of some dairy traits in Friesian cattle in Egypt. J Anim Breed Genet 108, 349-54

Mahdy AE, El-Shafie OM, Ayyat MS (1999) Genetic study and sire values for some economic traits in Egyptian buffaloes. Alexandria J Agric Res 44, 15-34

MALR (2006) Annual Statistics, Animal Sector, Ministry of Agriculture and Land Reclamation, Dokki, Cairo, Giza, Egypt [in Arabic]

Mostageer A, Morsy MA, Sadek RR (1981) The production characteristics of a herd of Buffaloes. Z Tierzücht Züchtgsbiol 98, 220-36

Mrode RA (1996) Linear models for the prediction of animal breeding values. CAB International Wallingford, UK

Rosati A, Van Vleck LD (2002) Estimation of genetic parameters for milk fat protein and mozzarella cheese production for the Italian river buffalo Bubalus bubalis population. Livest Prod Sci 74, 185-190

SAS Institute Inc (1996) SAS/Stat User's Guide version 8.5

Thevamanoharan K (2003) Genetic analysis of performance traits of Swamp and River buffalo Buffalo Newsletter 18, 11 Abstract

Tonhati H, Vasconcellos FB, Albquerque LG (2000) Genetic aspects of productive and reproductive traits in a Murrah buffalo herd in São Paulo, Brazil. J Anim Breed Genet 117, 331-6

Corresponding author:

ADEL SALAH KHATTAB

email: adelkhattab@yahoo.com

Animal Production Department, Faculty of Agriculture, University of Tanta, Tanta, Egypt 